\title{
Platelet-Activating Factor Acetylhydrolases: Broad Substrate Specificity and Lipoprotein Binding Does Not Modulate the Catalytic Properties of the Plasma Enzyme
}

\author{
Jung-Hyun Min,, Cheryl Wilder," Junken Aoki, ${ }^{\ddagger}$ Hiroyuki Arai, ${ }^{\#}$ Keizo Inoue, ${ }^{\#}$ Leland Paul," and \\ Michael H. Gelb*,\$, \\ Departments of Biochemistry and Chemistry, University of Washington, Seattle, Washington 98195, ICOS Corporation, \\ Bothell, Washington 98021, and Department of Health Chemistry, Graduate School of Pharmaceutical Sciences, \\ University of Tokyo, 7-3-1 Hongo, Bunkyo-ku, Tokyo 113, Japan
}

Received November 10, 2000

\begin{abstract}
Platelet-activating factor acetylhydrolases (PAF-AHs) are a group of enzymes that hydrolyze the sn-2 acetyl ester of PAF (phospholipase $\mathrm{A}_{2}$ activity) but not phospholipids with two long fatty acyl groups. Our previous studies showed that membrane-bound human plasma PAF-AH (pPAF-AH) accesses its substrate only from the aqueous phase, which raises the possibility that this enzyme can hydrolyze a variety of lipid esters that are partially soluble in the aqueous phase. Here we show that pPAF-AH has broad substrate specificity in that it hydrolyzes short-chain diacylglycerols, triacylglycerols, and acetylated alkanols, and displays phospholipase $\mathrm{A}_{1}$ activity. On the basis of all of the substrate specificity results, it appears that the minimal structural requirement for a good pPAF-AH substrate is the portion of a glyceride derivative that includes an $s n-2$ ester and a reasonably hydrophobic chain in the position occupied by the $s n-1$ chain. In vivo, pPAF-AH is bound to high and low density lipoproteins, and we show that the apparent maximal velocity for this enzyme is not influenced by lipoprotein binding and that the enzyme hydrolyzes tributyroylglycerol as well as the recombinant pPAF-AH does. Broad substrate specificity is also observed for the structurally homologous PAF-AH which occurs intracellularly [PAF-AH(II)] as well as for the PAF-AH from the lower eukaryote Physarum polycephalum although pPAF-AH and PAF-AH(II) tolerate the removal of the $s n-3$ headgroup better than the PAF-AH from P. polycephalum does. In contrast, the intracellular PAF-AH found in mammalian brain [PAF-AH(Ib) $\alpha 1 / \alpha 1$ and $\alpha 2 / \alpha 2$ homodimers] is more selectively operative on compounds with a short acetyl chain although this enzyme also displays significant phospholipase $A_{1}$ activity.
\end{abstract}

Platelet-activating factor (PAF; 1-O-alkyl-2-acetyl-snglycero-3-phosphocholine $)^{1}$ is a phospholipid autacoid implicated in many allergic and inflammatory responses (reviewed in ref 1). PAF is produced upon diverse proinflammatory stimulation under tight enzymatic regulation and activates cells such as platelets, neutrophils, monocytes, macrophages, and smooth muscle cells through a PAFspecific G-protein coupled receptor. The biological actions of PAF via the PAF receptor can be mimicked by oxidized phospholipids produced by oxidative modification of membrane phospholipids and of low-density lipoproteins (LDL) via free radical reactions (2). Such oxidized phospholipids are involved in vascular inflammation and atherosclerosis $(3,4)$.

The bioactivities of PAF and oxidized phospholipids are abolished by the hydrolysis of their $s n-2$ ester by PAFacetylhydrolases (PAF-AHs). PAF-AHs have been found in

\footnotetext{
Department of Biochemistry, University of Washington.

$\S$ Department of Chemistry, University of Washington.

"ICOS Corporation.

\# University of Tokyo.

* To whom correspondence should be addressed. Michael H. Gelb, Departments of Chemistry and Biochemistry, Box 351700, University of Washington, Seattle, WA 98195; 206-543-7142 (office); 206-6858665 (fax); gelb@chem.washington.edu.
}

blood plasma and in the intracellular fluid of various cells and organisms (5-7). Plasma PAF-AH (pPAF-AH) is a 45$\mathrm{kDa}$ protein associated primarily with small, dense LDL and high density lipoproteins (HDL) $(8-10)$. It has been reported that $4 \%$ of the Japanese population lack pPAF-AH and that such a deficiency or decrease in pPAF-AH activity is a risk factor for severity in asthma and atopy $(11-13)$. In animal models, recombinant pPAF-AH was effective in treating acute pancreatitis (14), asthma (15), anaphylactic shock (16), etc. Recombinant pPAF-AH is being tested in clinical trials with patients at risk for developing acute respiratory distress syndrome (17).

\footnotetext{
${ }^{1}$ Abbreviations: C10-PAF, 1-decanoyl-2-acetyl-sn-glycero-3-phosphocholine; C14-PAF, 1-myristoyl-2-acetyl-sn-glycero-3-phosphocholine; C16-PAF, 1-O-hexadecyl-2-acetyl-sn-glycero-3-phosphocholine; C18-PAF, 1-O-octadecyl-2-acetyl-sn-glycero-3-phosphocholine; 2-C16PAF, 1-acetyl-2- $O$-hexadecyl-rac-glycero-3-phosphocholine; $\left[{ }^{3} \mathrm{H}\right] \mathrm{C} 10$ PAF, 1-decanoyl-2-(1-[ $\left[{ }^{3} \mathrm{H}\right]$ acetyl)-sn-glycero-3-phosphocholine; $\left[{ }^{3} \mathrm{H}\right]-$ C16-PAF, 1-O-hexadecyl-2-(1-[ $\left.{ }^{3} \mathrm{H}\right]$ acetyl)-sn-glycero-3-phosphocholine; CHAPS, (3-[(3-cholamidopropyl)dimethylammonio]-1-propanesulfonate); $\mathrm{CMC}$, critical micelle concentration; EIA, enzyme immunoassay; HDL, high-density lipoproteins; LDL, low-density lipoproteins; PAF, plateletactivating factor; PAF-AH(II), human intracellular PAF acetylhydrolase isoform II; pPAF-AH, human plasma PAF acetylhydrolase; Physarum PAF-AH, PAF acetylhydrolase from Physarum polycephalum; PC, phosphatidylcholine.
} 
PAF-AH(II) is a $40-\mathrm{kDa}$, intracellular PAF-AH highly expressed in liver and kidney, and it shares $41 \%$ sequence identity with pPAF-AH. pPAF-AH and PAF-AH(II) do not distinguish between an ester or an ether at the $s n-1$ position of PAF or PAF analogues (18), and both can hydrolyze phospholipids with short to medium length $s n-2$ acyl chains including truncated chains derived from oxidative cleavage of long-chain polyunsaturated fatty acyl groups (18). Activity of these enzymes toward phospholipids with two long (1418 carbons) fatty acyl chains is negligible (18-20).

Another intracellular form of PAF-AH, the PAF-AH(Ib) complex, has been found in brain. Bovine brain PAF-AH(Ib) complex consists of two 26-kDa catalytic subunits, $\alpha 1$ and $\alpha 2$, which share $63 \%$ sequence identity with each other, and a regulatory $45-\mathrm{kDa} \beta$-subunit which is the product of the Miller-Dieker lissencephaly gene (21). The amino acid sequences of these subunits have poor homology with pPAF$\mathrm{AH}$ or PAF-AH(II) (22). Biochemical analyses revealed that the $\alpha 1 / \alpha 2$ heterodimer and the $\alpha 2 / \alpha 2$ homodimer are the major catalytic units of embryonic and adult brain PAF-AHs, respectively (23). The $\alpha$-subunits of $\mathrm{PAF}-\mathrm{AH}(\mathrm{Ib})$ form catalytically active homodimers, $\alpha 1 / \alpha 1$ and $\alpha 2 / \alpha 2$, when individually expressed in E. coli. Previous studies have shown that PAF-AH(Ib) hardly hydrolyzes the PAF analogues with $s n-2$ propionyl and butyroyl moieties, displaying stricter specificity for the $s n-2$ acetyl group of a phosphoglyceride than does pPAF-AH or PAF-AH(II) (18).

A PAF-AH from the slime mold Physarum polycephalum (physarum PAF-AH) has been purified and cloned in an effort to understand PAF-hydrolyzing activities in lower organisms which may not possess PAF. This enzyme hydrolyzes oxidized phospholipids as well as PAF and has transacylase activity. It is a cytosolic enzyme that shows both cytosolic and membrane subcellular distribution; PAF-AH(II) behaves similarly (24). However, the amino acid sequence homology of physarum PAF-AH with other PAF-AHs is weak (24), and its substrate specificity has not been studied as extensively as the other PAF-AHs.

We have recently reported that vesicle-bound $\mathrm{pPAF}-\mathrm{AH}$ necessarily accesses its substrates from the aqueous phase (25). In such a mechanism, the aqueous solubility of substrate is an important factor for controlling the substrate specificity of the enzyme. This plus the fact that pPAF-AH was first identified only on the basis of its ability to hydrolyze PAF but not phospholipids with long $s n-2$ chains suggested that this enzyme may hydrolyze a diverse set of water-soluble esters besides PAF. In the present study, we have explored this possibility and have also carried out a detailed comparison of the substrate specificities of pPAF-AH, PAF-AH(II), PAF-AH(Ib), and physarum PAF-AH. In addition, we have examined the effect of lipoprotein association on the specific activity and substrate specificity of pPAF-AH.

\section{MATERIALS AND METHODS}

Materials. All 1,2-diacyl-sn-phosphatidylcholines, 1,2diacyl-sn-glycerols, dioctanoylethyleneglycol, and 1-oleoyl2-acetyl-sn-glycerol are from Avanti Polar Lipids and are stereochemically pure unless noted otherwise. Methyl butyrate is from Aldrich. C16-PAF and C18-PAF are from BioMol. 3-O-Octadecyl-2-acetyl-sn-glycero-1-phosphocholine is from Bachem. $\left[1-{ }^{3} \mathrm{H}\right]$ Acetic anhydride and $\left[{ }^{3} \mathrm{H}\right] \mathrm{C} 16-$
PAF are from NEN Life Science Products. All lysophosphocholines, triacylglycerols, 1(3)-monoacyl-rac-glycerols, butyl-, octyl- acetates, gentamicin sulfate, diethylenetriaminepentaacetic acid, Antifoam A, and the Cholesterol Reagent are from Sigma. 2-Monoolein (2-oleoylmonoacylglycerol) is from Serdary Research Laboratories (London, Ontario). C10-PAF was prepared as described (25). Tributyroylglycerol[butyric- $1-{ }^{14} \mathrm{C}$ ] is from American Radiolabled Chemicals Inc. Trolox is from Calbiochem. BCA (bicinchoninic acid) reagent, streptavidin-horseradish peroxidase, nitroblue tetrazolium chloride, and 5-bromo-4-chloro-3'-indolyphosphate- $p$-toluidine solution are from Promega. Sheep antihuman-apolipoprotein AI and B immunoglobulins are from Boehringer Mannheim Biochemica. Recombinant pPAF-AH was expressed in E. coli and purified as described (26). Recombinant forms of human PAF-AH(II), physarum PAF$\mathrm{AH}$, and bovine PAF-AH(Ib) $\alpha 1 / \alpha 1$ and $\alpha 2 / \alpha 2$ homodimers were purified as described $(24,27)$.

Synthesis of 1-Acetyl-2-O-hexadecyl-rac-phosphocholine (2-C16-PAF). 1-Hydroxy-2-O-hexadecyl-rac-phosphocholine was a generous gift from Dr. H. S. Hendrickson and E. K. Hendrickson (University of Washington). Acetylation of this lysophospholipid $(0.1 \mathrm{mmol})$ was done with acetic anhydride $(\sim 0.5 \mathrm{mmol})$ in $5 \mathrm{~mL}$ of $\mathrm{CH}_{2} \mathrm{Cl}_{2}$ containing $4-(N, N-$ dimethylamino)pyridine $(0.1 \mathrm{mmol})(28)$, and the product was purified by flash chromatography over $2 \mathrm{~g}$ of silica gel with a chloroform/methanol/water step gradient as follows: $150 \mathrm{~mL}$ of chloroform/methanol $(90: 10 \mathrm{v} / \mathrm{v}), 100 \mathrm{~mL}$ of chloroform/methanol (80:20), $100 \mathrm{~mL}$ of chloroform/ methanol (65:35), $20 \mathrm{~mL}$ of chloroform/methanol/water (65: $35: 1), 20 \mathrm{~mL}$ of chloroform/methanol/water $(65: 35: 2), 20$ $\mathrm{mL}$ of chloroform/methanol/water (65:35:3), $40 \mathrm{~mL}$ of chloroform/methanol/water (65:35:4), and $36 \mathrm{~mL}$ of chloroform/methanol/ammonia/water (20:14:1:1). Fractions containing PC were pooled, and solvent was removed with a rotary evaporator. The purity and the structure of the product were confirmed by TLC and NMR. The amount of phosphate was determined using the Ames method (29).

Synthesis of $\left[{ }^{3} \mathrm{H}\right] \mathrm{C} 10-\mathrm{PAF}$. Acetylation of 1-decanoyl-2hydroxy-sn-glycero-3-phosphocholine $(0.10 \mathrm{mmol})$ was done with $\left[1-{ }^{3} \mathrm{H}\right]$ acetic anhydride $(0.25 \mathrm{mmol}, 50.00 \mathrm{mCi} / \mathrm{mmol}$, NEN Life Science Products) in $10 \mathrm{~mL}$ of $\mathrm{CH}_{2} \mathrm{Cl}_{2}$ containing 4 - $(N, N$-dimethylamino)pyridine $(0.48 \mathrm{mmol})$ at room temperature for $6 \mathrm{~h}$. The product was purified over silica gel as described for the nonradioactive synthesis of C10-PAF (25, 28). The purity was confirmed by TLC followed by fluorography using $\mathrm{EN}^{3} \mathrm{HANCER}$ spray (NEN), and the amount of the product was determined by liquid scintillation counting.

Titrimetric PAF-AH Assay. The standard titrimetric $\mathrm{pH}-$ stat assay was done as previously described (30) at $22 \pm 1$ ${ }^{\circ} \mathrm{C}$ unless noted otherwise. The reaction mixture contained substrate at the desired concentration in $5 \mathrm{~mL}$ of $1 \mathrm{mM} \mathrm{NaCl}$ solution, and the reaction was initiated by adding enzymes diluted from stock solutions. While the amount of enzymes used varied $(0.24-20 \mu \mathrm{g})$ depending on the substrate, a fixed amount was employed for one substrate as the substrate concentration was varied. The stock solution of recombinant pPAF-AH was prepared in $50 \mathrm{mM}$ sodium phosphate, $\mathrm{pH}$ $7.5,125 \mathrm{mM} \mathrm{NaCl}, 0.1 \%$ Pluronic F68, and 0.02\% Tween 80 at an enzyme concentration of $4 \mathrm{mg} / \mathrm{mL}$. Stock solutions of other PAF-AHs were prepared in $10 \mathrm{mM}$ Tris- $\mathrm{HCl}, \mathrm{pH}$ 
$7.4,150 \mathrm{mM} \mathrm{NaCl}$, and $10 \%$ glycerol (except for physarum PAF-AH which had 50\% glycerol) at enzyme concentrations of $0.375 \mathrm{mg} / \mathrm{mL}$ for PAF-AH(II), $1.0 \mathrm{mg} / \mathrm{mL}$ for physarum PAF-AH, $0.65 \mathrm{mg} / \mathrm{mL}$ for PAF-AH(Ib) $\alpha 1 / \alpha 1$ homodimer, and $1.0 \mathrm{mg} / \mathrm{mL}$ for $\alpha 2 / \alpha 2$ homodimer. The enzyme concentrations were measured using BCA reagent (31) with bovine serum albumin as a standard. Ethanol was used for preparing diluted stock solutions of diacylglycerols, dioctanoylethyleneglycol, triacylglycerols, and octyl acetate, and the volume of ethanol added to the reaction mixture was not more than $4 \%$ of the reaction volume. When undiluted substrate solutions were used, the maximum percent volumes added were $5 \%$ for methyl butyrate, $8 \%$ for triacetylglycerol, and $4 \%$ for butyl acetate. The other substrates were prepared in $1 \mathrm{mM} \mathrm{NaCl}$ solution. The rates were measured by subtracting the slope of the reaction progress curve for the last three minutes before adding enzyme from the slope from the first to the fourth minute after adding enzyme.

Preparation of Plasma. Blood from healthy, normolipidemic donors was collected into EDTA $(0.37 \mathrm{M}$ stock solution)- and diethylenetriaminepentaacetic acid (100 mM stock solution)-containing tubes after an overnight fast. The final concentrations of EDTA and diethylenetriaminepentaacetic acid were 4.3 and $0.1 \mathrm{mM}$, respectively. The blood was centrifuged at $2500 \mathrm{rpm}\left(1180 \mathrm{~g}_{\mathrm{av}}\right)$ for $30 \mathrm{~min}$ at $10-12$ ${ }^{\circ} \mathrm{C}$ in a Beckman GS-6R centrifuge. Gentamicin sulfate (10 $\mathrm{mg} / \mathrm{mL}$ stock solution) and Trolox (10 $\mathrm{mM}$ stock solution) were added to the supernatant immediately after its collection to final concentrations of $50 \mu \mathrm{g} / \mathrm{mL}$ and $10 \mu \mathrm{M}$, respectively.

Isolation of LDL Subfractions by $\mathrm{D}_{2} \mathrm{O}$-Density Gradient Isopycnic Ultracentrifugation. LDL density subfractions were prepared by isopycnic density gradient ultracentrifugation using a $\mathrm{D}_{2} \mathrm{O}$ gradient as previously described (32). In brief, the density of plasma was adjusted with $\mathrm{D}_{2} \mathrm{O}$ saline to 1.072 $\mathrm{g} / \mathrm{mL}$ in a total volume of $5.0 \mathrm{~mL}$ containing $2.0 \mathrm{~mL}$ of plasma. The solution was layered underneath a $\mathrm{D}_{2} \mathrm{O}-\mathrm{H}_{2} \mathrm{O}$ saline solution $(d=1.025 \mathrm{~g} / \mathrm{mL}, 7.3 \mathrm{~mL})$ in a Beckman centrifuge tube $(9 / 16 \times 3.5 \mathrm{in})$, and the sample was centrifuged at $41000 \mathrm{rpm}\left(288000 g_{\text {av }}\right)$ for $48 \mathrm{~h}$ at $12{ }^{\circ} \mathrm{C}$ in a Beckman SW41Ti rotor. The saline solutions consist of $195 \mathrm{mM} \mathrm{NaCl}, 1 \mathrm{mM}$ EDTA, $0.1 \mathrm{mM}$ diethylenetriaminepentaacetic acid, $50 \mu \mathrm{g} / \mathrm{mL}$ gentamicin sulfate, and $10 \mu \mathrm{M}$ Trolox, $\mathrm{pH} 7.5$, in appropriate mixtures of $\mathrm{D}_{2} \mathrm{O}$ and $\mathrm{H}_{2} \mathrm{O}$. Fractions of $0.40 \mathrm{~mL}$ were collected using a Gilson FC203 fraction collector and a Beckman fraction recovery system at $1 \mathrm{~mL} / \mathrm{min}$ as the solution was eluted from the top by introducing a dense $\mathrm{KBr}$ solution $(d=1.3 \mathrm{~g} / \mathrm{mL})$ from the bottom at the same rate. Each fraction was filtered through a sterile $0.20 \mu$ filter (Corning, Cat. No. 431219), stored at $4{ }^{\circ} \mathrm{C}$, and used within 10 days. The apolipoprotein Bcontaining lipoproteins (LDL) were well separated from the apolipoprotein AI-containing lipoproteins (HDL) and albumin as determined by Western blot analysis (see below).

Analyses of Lipoprotein Fractions. The density of each fraction at room temperature was measured gravimetrically by weighing $100 \mu \mathrm{L}$ of each fraction of a control experiment in which saline solution was employed in place of plasma. SDS-PAGE was carried out using a 4-20\% gradient TrisGlycine gel (Novex) with $10-16 \mu \mathrm{L}$ of a lipoprotein fraction per well. Western blot analyses for apolipoprotein B and AI were performed on PVDF membrane using sheep antihuman-apolipoprotein B and AI antibodies and alkaline phosphatase-linked goat antisheep antibody as the secondary antibody. Detection was carried out with nitro-blue tetrazolium chloride and 5-bromo-4-chloro-3'-indolyphosphate- $p$ toluidine solution (33). Protein concentrations of the fractions were determined using the BCA reagent as described (31) with a standard curve using $0.0-2.0 \mathrm{mg} / \mathrm{mL}$ bovine serum albumin solution (Pharmacia). Total cholesterol concentration was measured using the enzymatic endpoint reagent kit (Sigma).

Isolation of Plasma Lipoprotein Fractions by KBr-Density Gradient Ultracentrifugation. HDL and LDL were prepared by a single, discontinuous density gradient ultracentrifugation using a $\mathrm{KBr}$ gradient (34). The $\mathrm{KBr}$ density gradient was used instead of the $\mathrm{D}_{2} \mathrm{O}$ density gradient to separate a broader range of lipoproteins. Plasma $(200 \mu \mathrm{L})$ was mixed with 1.8 $\mathrm{mL}$ of $\mathrm{KBr}-\mathrm{PBS}$ solution $(d=1.38 \mathrm{~g} / \mathrm{mL})$, and $1.9 \mathrm{~mL}$ of the mixture was layered underneath $3.5 \mathrm{~mL}$ of PBS solution $(d=1.006 \mathrm{~g} / \mathrm{mL})$ in a Beckman Ultraclear centrifuge tube $(0.5 \times 2$ in). The ultracentrifugation was carried out in a Beckman SW55Ti rotor at $55000 \mathrm{rpm}\left(368000 g_{\mathrm{av}}\right)$ at 10 ${ }^{\circ} \mathrm{C}$ for $3 \mathrm{~h}$. Fractions of $0.23 \mathrm{~mL}$ were collected by eluting the solution from the bottom using a peristaltic pump at 1 $\mathrm{mL} / \mathrm{min}$.

To check the effect of KBr on pPAF-AH activity and EIA, pooled fractions of HDL (fractions 7-9; $d=1.14-1.18$ $\mathrm{g} / \mathrm{mL}$ ) and LDL (fractions $12-14 ; d=1.03-1.06 \mathrm{~g} / \mathrm{mL}$ ) were dialyzed overnight at $4{ }^{\circ} \mathrm{C}$ against phosphate-buffered saline $\left(8.1 \mathrm{mM} \mathrm{Na}_{2} \mathrm{HPO}_{4}, 1.5 \mathrm{mM} \mathrm{KH}_{2} \mathrm{PO}_{4}, 137 \mathrm{mM} \mathrm{NaCl}\right.$, $2.7 \mathrm{mM} \mathrm{KCl}, 1 \mathrm{mM}$ EDTA, and $0.1 \mathrm{mM}$ diethylenetriaminepentaacetic acid, $\mathrm{pH}$ 7.5), and the radiometric pPAF-AH assay and EIA were done on the dialyzed fractions and on the undialyzed ones. $\mathrm{KBr}$ did not alter the results of the assays, and the recovery after dialysis was $\sim 90 \%$ for both the pooled HDL and LDL fractions. Thus, undialyzed fractions were used for further studies.

Radiometric PAF-AH Assay. Radiometric assays for pPAF-AH were performed as previously described (35) with minor modification using a Biomek 2000 automatic pipetting station with 96-well microplates. The assay buffer (pPAFAH assay buffer) was composed of $25 \mathrm{mM}$ Tris- $\mathrm{HCl}, \mathrm{pH}$ $7.5,0.5 \mathrm{M} \mathrm{NaCl}$, and $1 \mathrm{mM}$ EDTA with a specified concentration of CHAPS and $\left[{ }^{3} \mathrm{H}\right] \mathrm{C} 16-\mathrm{PAF},\left[{ }^{3} \mathrm{H}\right] \mathrm{C} 10-\mathrm{PAF}$, or tributyroylglycerol[butyric- $1-{ }^{14} \mathrm{C}$ ] in a total volume of 100 $\mu \mathrm{L}$. The reaction was initiated by the addition of $20 \mu \mathrm{L}$ of enzyme solution previously diluted in the same buffer as the substrate. At least three different dilutions of enzyme solution were included in one plate. The incubation was done at 37 ${ }^{\circ} \mathrm{C}$ for $15 \mathrm{~min}$, and the reaction was quenched by adding $125 \mu \mathrm{L}$ of activated charcoal suspension $(25 \mathrm{mg} / \mathrm{mL})$. The plate was centrifuged at $2700 \mathrm{rpm}\left(1400 g_{\mathrm{av}}\right)$ for $10 \mathrm{~min}$ at 5 ${ }^{\circ} \mathrm{C}$ in a Beckman GS-6R centrifuge using a Microplate carrier for a Beckman GH 3.7 rotor. Radioactivity in the supernatant was counted in a Wallac Microbeta liquid scintillation counter to determine the amount of free $\left[1-{ }^{3} \mathrm{H}\right]$ acetic acid. Only the data giving less than $30 \%$ of total substrate hydrolysis were used to determine the initial rates, and the results are expressed as micromoles of substrate hydrolyzed per hour per milliliter of enzyme solution after correction for nonenzymatic degradation of the substrate.

When the activity of exogenously added recombinant pPAF-AH was measured, $10 \mu \mathrm{L}$ of a stock solution of purified recombinant pPAF-AH $(8.1 \mathrm{nM}$ in $25 \mathrm{mM}$ Tris- 
$\mathrm{HCl}, \mathrm{pH} 7.5,0.5 \mathrm{M} \mathrm{NaCl}, 1 \mathrm{mM}$ EDTA, and 6 mM CHAPS) was added to $100 \mu \mathrm{L}$ of each lipoprotein fraction sample, and the mixture was incubated for $30 \mathrm{~min}$ at room temperature and then processed as described above.

Quantitative Enzyme Immunoassay (EIA) of pPAF-AH. A 96-well polystyrene plate (Immulon 4 "C" Bottom Dividastrip plate) was coated with purified anti-recombinant pPAFAH murine monoclonal antibody, 90G11D [prepared by the in-house facility at ICOS, $125 \mu \mathrm{L} / \mathrm{well}, 2.5 \mu \mathrm{g} / \mathrm{mL}$ in $50 \mathrm{mM}$ sodium carbonate/bicarbonate $\mathrm{pH}$ 9.6, 0.05\% Proclin 300 (Supelco)] at $37{ }^{\circ} \mathrm{C}$ for $2 \mathrm{~h}$. The coating solution was removed, and the plate was incubated with blocking solution ( $300 \mu \mathrm{L} /$ well, $50 \mathrm{mM}$ sodium citrate, $\mathrm{pH} 7.4,145 \mathrm{mM} \mathrm{NaCl}$, $25 \mathrm{~g} / \mathrm{L}$ dry nonfat milk, $0.005 \%$ Antifoam A, and $0.05 \%$ Proclin 300) at room temperature for $30 \mathrm{~min}$. Samples were diluted 6- to 101-fold, and standards were prepared at eight different concentrations between 0 and $10 \mathrm{ng} / \mathrm{mL}(0-0.22$ $\mathrm{nM})$ from a recombinant pPAF-AH stock solution $(4 \mathrm{mg} /$ $\mathrm{mL}$ in $50 \mathrm{mM}$ sodium phosphate, $\mathrm{pH} 7.5,125 \mathrm{mM} \mathrm{NaCl}$, $0.1 \%$ Pluronic F68, and $0.02 \%$ Tween 80 ). The same diluent buffer was used for both samples and standards $(50 \mathrm{mM}$ sodium citrate, $\mathrm{pH} 7.4,145 \mathrm{mM} \mathrm{NaCl}, 7.5 \mathrm{mM}$ CHAPS, 50 $\mathrm{g} / \mathrm{L}$ dry nonfat milk, $2.5 \%$ horse serum, $0.005 \%$ Antifoam A, $0.05 \%$ Tween 20, $0.05 \%$ Proclin 300, and $0.015 \%$ Blue food color). Sample or standard solution (100 $\mu \mathrm{L} /$ well) was added to the plate after the removal of the blocking solution, and the plate was incubated at $37{ }^{\circ} \mathrm{C}$ for $30 \mathrm{~min}$. The plate was then washed 5 times with $145 \mathrm{mM} \mathrm{NaCl}, 0.05 \%$ Tween 20 using a microplate washer (Biotek EL403H). The secondary antibody, biotinylated anti-recombinant $\mathrm{pPAF}-\mathrm{AH}$ murine monoclonal antibody, 90F2D (prepared by the in-house facility at ICOS) was added $(100 \mu \mathrm{L} /$ well in the biotin conjugate buffer made of $20 \mathrm{mM}$ sodium citrate, $\mathrm{pH} 7.0$, $0.5 \mathrm{M} \mathrm{NaCl}, 6.3 \mathrm{~g} / \mathrm{L}$ dry nonfat milk, $0.25 \mathrm{~g} / \mathrm{L}$ goat gamma globulin, $0.005 \%$ Antifoam A, $0.2 \%$ Tween 20, $0.05 \%$ Proclin 300, and $0.025 \%$ Red food color), and the plate was incubated at $37^{\circ} \mathrm{C}$ for $30 \mathrm{~min}$. The plate was washed as previously described and incubated with streptavidinhorseradish peroxidase (Promega, $100 \mu \mathrm{L} / \mathrm{well}, 0.5 \mu \mathrm{g} / \mathrm{mL}$ in the biotin conjugate buffer) at $37^{\circ} \mathrm{C}$ for $30 \mathrm{~min}$, followed by another wash step. Subsequently, substrate solution for the peroxidase $(100 \mu \mathrm{L} /$ well, $0.1 \mathrm{M}$ sodium acetate, $\mathrm{pH} 5.5$, $0.015 \%$ hydrogen peroxide, and $0.42 \mathrm{mM}$ tetramethylbenzidine) was added, and the plate was incubated at room temperature for $30 \mathrm{~min}$ in the dark. The reaction was stopped by adding $100 \mu \mathrm{L}$ of $1 \mathrm{~N} \mathrm{H}_{2} \mathrm{SO}_{4}$. The absorbance of each well was read at 450 and $630 \mathrm{~nm}$ using a microplate reader (SpectraMax 250). The difference $A_{450}-A_{630}$ was used for calculation. Only the sample data that gave values within the standard range were used.

\section{RESULTS}

Substrate Specificity of $p P A F-A H$. The substrate specificity of pPAF-AH was examined by measuring the initial hydrolysis rates of various substrates at different concentrations using a pH-stat as described in Materials and Methods. Hyperbolic kinetics (apparent saturation) was observed in the velocity versus substrate concentration plots (not shown), and the apparent $V_{\max }\left(V_{\max , a p p}\right)$ and $K_{\mathrm{m}}\left(K_{\mathrm{m} \text {,app }}\right)$ values were obtained from the fit of the data to the classical MichaelisMenten equation. In some cases, the $K_{\text {m,app }}$ value was too low to measure with the $\mathrm{pH}$-stat assay (Table 1). As
Table 1: Substrate Specificity of pPAF-AH ${ }^{a}$

\begin{tabular}{lll}
\hline \multicolumn{1}{c}{ substrate } & \multicolumn{1}{c}{$V_{\text {max,app }}\left(\mathrm{s}^{-1}\right)$} & \multicolumn{1}{c}{$K_{\text {m,app }}(\mu \mathrm{M})$} \\
\hline C18-PAF & $6.6 \pm 0.5$ & $<5$ \\
C16-PAF & $26 \pm 1$ & $<5$ \\
dibutyroyl-PC & $12 \pm 1$ & $4700 \pm 700$ \\
dioctanoyl-PC & $25 \pm 1$ & $47 \pm 9$ \\
didecanoyl-PC & $5.3 \pm 0.2$ & $<5$ \\
1-oleoyl-2-acetyl-sn-glycerol & $2.0 \pm 0.1$ & $5.9 \pm 1.5$ \\
1,2-dioctanoyl-sn-glycerol & $5.1 \pm 0.2$ & $<5$ \\
1,2-didecanoyl-sn-glycerol & $0.60 \pm 0.04$ & $11 \pm 3$ \\
1,2-dioctanoylethyleneglycol & $0.43 \pm 0.02$ & $<5$ \\
1-monooctanoyl-rac-glycerol & $0.32 \pm 0.02$ & $1400 \pm 300$ \\
1-monodecanoyl-rac-glycerol & $0.068 \pm 0.004$ & $86 \pm 24$ \\
triacetylglycerol & $33 \pm 2$ & $131000 \pm 19000$ \\
tributyroylglycerol & $12 \pm 1$ & $136 \pm 29$ \\
trioctanoylglycerol & $\ll 5$ & not determined \\
methyl butyrate & $3.8 \pm 0.4$ & $143000 \pm 51000$ \\
butyl acetate & $0.96 \pm 0.12$ & $63000 \pm 22000$ \\
octyl acetate & $0.41 \pm 0.02$ & $55 \pm 10$ \\
2-C16-PAF & $8.1 \pm 0.6$ & $<5$ \\
3-octadecyl-2-acetyl-sn-glycero- & $<0.2$ & not determined \\
\multicolumn{1}{l}{ 1-phosphocholine } & & \\
\hline
\end{tabular}

${ }^{a}$ See text for a discussion of the apparent kinetic parameters.

described previously (25), hyperbolic kinetics does not necessarily imply saturation of the active site of pPAF-AH with substrate. To a first approximation, the concentration of substrate in the aqueous phase cannot exceed its CMC. Thus, in the context of the aqueous phase mechanism for pPAF-AH, the enzymatic rate cannot increase further once the concentration of substrate in the aqueous phase reaches a constant amount determined by its solubility. This is true in the presence and absence of a vesicle or lipoprotein interface to which pPAF-AH may be bound. Thus, it is important to refer to the kinetic parameters derived from the velocity versus substrate concentration plots as apparent kinetic values. In addition, the binding of pPAF-AH to vesicles of phosphatidylcholine or phosphatidylmethanol does not significantly alter the catalytic efficiency of the enzyme toward PAF and PAF analogues in the aqueous phase, i.e., little interfacial activation (25). Thus, we decided to carry out substrate specificity studies of this enzyme in the absence of a phospholipid interface.

As shown in Table $1, V_{\max , a p p}$ for the hydrolysis of C16$\mathrm{PAF}$ by pPAF-AH is 4-fold higher than that for C18-PAF hydrolysis, presumably due to the higher aqueous phase solubility of the former as compared to the latter. pPAF-AH displays poor activity toward phospholipids with 16- to 18carbon long $s n-1$ chains and an $s n-2$ chain of 8 carbons (without oxygen atoms from oxidation) $(19,25)$. We reasoned, in terms of the aqueous phase mechanism for pPAF-AH action, that $s n-2$ acyl chains longer than acetyl would be tolerated if the $s n-1$ chain were shorter than the typical 16- to 18-carbon long chains found in cell phospholipids. As shown in Table 1, dibutyroyl-PC, dioctanoyl-PC, and didecanoyl-PC are all respectable substrates for pPAF$\mathrm{AH}$, although the $K_{\mathrm{m} \text {,app }}$ value for dibutyroyl-PC is higher relative to those of the other substrates. These results establish that the active site of pPAF-AH does not exclude phospholipids with $s n-2$ fatty acyl chains significantly longer than 2-carbons. The aqueous phase mechanism also explains why pPAF-AH can efficiently hydrolyze phospholipids with oxidatively truncated $s n-2$ fatty acyl chains $(20,36)$, a result that also confirms that this enzyme does not exclude substrates with $s n-2$ chains longer than acetyl. The results 
with the diacyl-PC series of increasing fatty acyl chain length show that the enzyme prefers substrates that are more hydrophobic than dibutyroyl-PC, within the limit set by aqueous phase solubility of the substrate.

In our previous study (25), we found that pPAF-AH does not significantly discriminate against PAF analogues in which the choline portion of the polar headgroup is replaced with ethanolamine, glycerol, serine, and hydrogen. The relatively small differences in the rate of hydrolysis of this series of substrates are controlled mainly by their aqueous phase solubility (25). In the present study, we explored the requirement of the $s n-3$ phosphate group of PAF for recognition by pPAF-AH. As shown in Table 1, the diacylglycerols, 1-oleoyl-2-acetyl-sn-glycerol and 1,2-dioctanoyl$s n$-glycerol, are all efficiently hydrolyzed by pPAF-AH. Values of $V_{\max \text {,app }}$ for the diacylglycerols were 5-10-fold lower than the values for the corresponding phosphocholines, presumably due to the lower aqueous phase solubility of diacylglycerols versus the diacylphosphocholines. For example, the CMC of dihexanoylglycerol $(0.54 \mathrm{mM})$ is 14 fold lower than the CMC of dihexanoyl-PC (7.6 mM) (37). Dioctanoylethyleneglycol lacking the $s n-3-\mathrm{CH}_{2}-\mathrm{OH}$ of $1,2-$ dioctanoyl-sn-glycerol showed a $\sim 12$-fold lower rate than 1,2-dioctanoyl-sn-glycerol, which may also be due to the lower aqueous phase solubility of dioctanoylethyleneglycol resulting from the absence of the polar $\mathrm{CH}_{2}-\mathrm{OH}$ moiety. These results show that a phosphate headgroup is not an essential part of PAF for recognition by pPAF-AH, while an $s n-3$ polar headgroup improves the efficiency of substrate hydrolysis presumably by increasing the solubility of the substrate in the aqueous phase.

Despite the higher aqueous phase solubility of monoacylglycerols versus diacylglycerols [for example, the CMC of monohexanoylglycerol is $\sim 200$ times higher than that of dihexanoylglycerol (37)], the racemic mixtures of 1- and 3-monoacylglycerols displayed 9-16-fold lower values of $V_{\text {max,app }}$ than the corresponding diacylglycerols (Table 1). These results again support the notion that pPAF-AH prefers more hydrophobic substrates, within the limit of aqueous phase solubility. The hydrolysis of 2-monoolein was not detectable (not shown).

In support of the above observations showing that a polar headgroup is not required for pPAF-AH substrates, we found that triacylglycerols with short acyl chains, triacetylglycerol, and tributyroylglycerol are efficiently hydrolyzed by pPAFAH (Table 1). Trioctanoylglycerol is poorly hydrolyzed presumably because of its low aqueous phase solubility. The relatively high $K_{\text {m,app }}$ for triacetylglycerol as compared to that of tributyroylglycerol again supports the preference of pPAF-AH for more hydrophobic substrates. No attempt was made to determine the immediate product of trioctanoylglycerol hydrolysis since the initially formed dioctanoylglycerol is expected to be a good substrate for pPAF-AH. This was apparent from the observation that a lag phase was seen during trioctanoylglycerol hydrolysis in the first few minutes of the reaction (not shown). The simple esters such as methyl butyrate, butyl acetate, and octyl acetate are all substrates for pPAF-AH, although values of $K_{\mathrm{m}, \mathrm{app}}$ for the less hydrophobic esters, methyl butyrate, and butyl acetate, are in the millimolar range (Table 1).

We also found that the isomer of PAF in which the acetyl group is at the $s n-1$ position and the hexadecyl ether is at
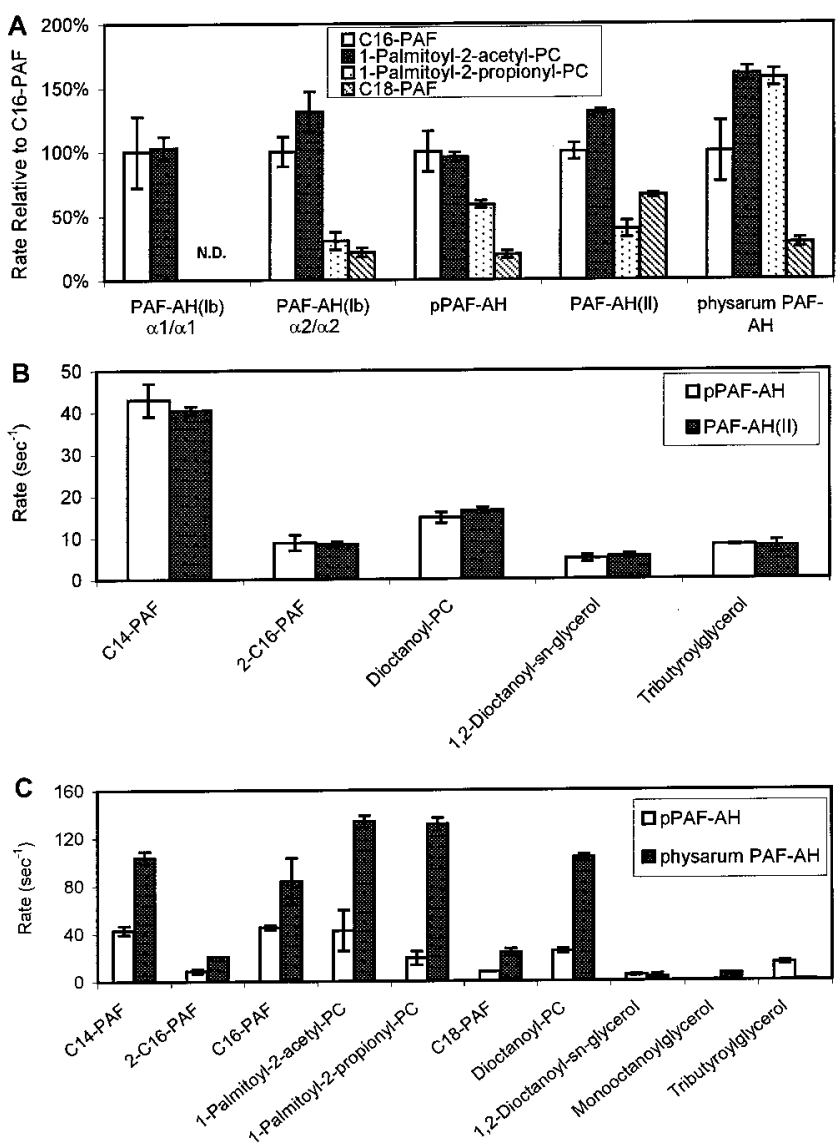

FIGURE 1: Substrate specificity comparison of various PAF-AHs. (A) Relative rates for the hydrolysis of PAF analogues by PAFAHs. The concentration of all substrates used was $100 \mu \mathrm{M}$. (B) Comparison of pPAF-AH and PAF-AH(II). The concentrations of substrates used were $50 \mu \mathrm{M}$ for C14-PAF, 2-C16-PAF, and 1,2dioctanoyl-sn-glycerol, $79 \mu \mathrm{M}$ for dioctanoyl-PC, and $160 \mu \mathrm{M}$ for tributyroylglycerol. (C) Comparison of pPAF-AH and physarum PAF-AH. The concentrations of substrates used were $50 \mu \mathrm{M}$ for C14-PAF, 2-C16-PAF, and 1,2-dioctanoyl-sn-glycerol, $100 \mu \mathrm{M}$ for C16-PAF, 1-palmitoyl-2-acetyl-PC, 1-palmitoyl-2-propionyl-PC, and C18-PAF, $157 \mu \mathrm{M}$ for dioctanoyl-PC, $1980 \mu \mathrm{M}$ for 1(3)monooctanoyl-rac-glycerol, and $319 \mu \mathrm{M}$ for tributyroylglycerol.

the $s n-2$ position, 2-C16-PAF, is a good substrate for pPAF$\mathrm{AH}$, comparable to C16-PAF (Table 1). This clearly shows that pPAF-AH has phospholipase $\mathrm{A}_{1}$ activity. Although 2-C16-PAF is racemic, pPAF-AH is able to hydrolyze all of the phospholipid present in the reaction mixture with no anomalous change in rate beyond $50 \%$ hydrolysis. Thus, both enantiomers are efficiently hydrolyzed. We also studied the enantiomer of C18-PAF, 3-octadecyl-2-acetyl-sn-glycero-1phoshocholine, and found that it was hydrolyzed very poorly, if at all, by pPAF-AH $\left(<0.2 \mathrm{~s}^{-1}\right)$ when tested at a concentration of $100 \mu \mathrm{M}$.

Substrate Specificities of PAF-AH(II), PAF-AH(Ib), and Physarum PAF-AH. The substrate specificities of other PAFAHs were examined by comparing the hydrolysis rates for several compounds tested at concentrations sufficient to give $V_{\text {max,app }}$ with pPAF-AH. Figure 1, panel A, shows the comparison of the action of five PAF-AHs acting on PAF and PAF analogues containing an ether versus an ester linked $s n-1$ chain or with an extended $s n-2$ fatty acyl chain. The turnover numbers for pPAF-AH, PAF-AH(II), PAF-AH(Ib) $\alpha 2 / \alpha 2$, PAF-AH(Ib) $\alpha 1 / \alpha 1$ and physarum PAF-AH acting on $50 \mu \mathrm{M}$ C14-PAF are $43,40,4.8,0.6$, and 103 , respec- 
Table 2: Substrate Specificity of pPAF-AH and PAF-AH(Ib $)^{a}$

\begin{tabular}{lccc}
\hline & pPAF-AH & PAF-AH(Ib) $\alpha 2 / \alpha 2$ & PAF-AH(Ib) $\alpha 1 / \alpha 1$ \\
\hline C16-PAF $50 \mu \mathrm{M}$ & $24.6 \pm 3.9$ & $3.2 \pm 0.4$ & $0.34 \pm 0.09$ \\
2-C16-PAF $50 \mu \mathrm{M}$ & $8.1 \pm 0.6$ & $1.1 \pm 0.1$ & $\mathrm{ND}$ \\
C18-PAF 50 $\mu \mathrm{M}$ & $4.8 \pm 0.7$ & $0.68 \pm 0.12$ & $\mathrm{ND}$ \\
1-oleoyl-2-acetyl-sn-glycerol $50 \mu \mathrm{M}$ & $3.0 \pm 0.4$ & $0.25 \pm 0.07$ & $\mathrm{ND}$ \\
octyl acetate $495 \mu \mathrm{M}$ & $0.28 \pm 0.06$ & $1.9 \pm 0.3$ & $0.69 \pm 0.14$ \\
triacetylglycerol $100 \mathrm{mM}$ & $16.5 \pm 3.9$ & $37.0 \pm 4.7$ & $101.3 \pm 14.8$ \\
\hline
\end{tabular}

${ }^{a}$ The numbers are the apparent turnover numbers expressed in units of $\mathrm{s}^{-1}$.

tively. For all enzymes, the rates for hydrolysis of C16-PAF and 1-palmitoyl-2-acetyl-PC are not significantly different ( $<1.6$-fold), showing little discrimination between an ester and an ether at the $s n-1$ position of PAF. Increasing the length of the $s n-2$ chain from acetyl to propionyl gave different effects depending on the enzyme. As compared to C16-PAF, physarum PAF-AH hydrolyzed 1-palmitoyl-2-propionyl-PC at a similar rate, pPAF-AH and PAF-AH(II) were about 2-fold less active on 1-palmitoyl-2-propionyl-PC, and PAF$\mathrm{AH}(\mathrm{Ib}) \alpha 2 / \alpha 2$ was about 4 -fold less active on 1-palmitoyl2-propionyl-PC as compared to C16-PAF (Figure 1, panel A). All of these four PAF-AHs show a decrease in activity as the $s n-1$ chain length was increased (compare C16-PAF to $\mathrm{C} 18-\mathrm{PAF}$ in Figure 1, panel A). The turnover numbers for PAF-AH(Ib) $\alpha 1 / \alpha 1$ acting on 1-palmitoyl-2-propionylPC and C18-PAF $\left(<0.1 \mathrm{~s}^{-1}\right)$ were significantly lower than those for the $\alpha 2 / \alpha 2$ homodimer acting on the same substrates and are not determined.

As shown in Figure 1, panel B, the substrate specificity profile for pPAF-AH and PAF-AH(II) toward lipid esters with and without a phosphate are very similar. The results show that PAF-AH(II), like pPAF-AH, has significant phospholipase $\mathrm{A}_{1}$ activity as well as significant activity toward short-chain diacyl- and triacyl-glycerols.

The specific activities of PAF-AH(Ib) $\alpha 2 / \alpha 2$ acting on 2-C16-PAF and C16-PAF are comparable, $1.1 \pm 0.1$ and $3.2 \pm 0.4 \mathrm{~s}^{-1}$, respectively, showing that the brain enzyme also has significant phospholipase $A_{1}$ activity (Table 2). The specific activity of PAF-AH(Ib) $\alpha 2 / \alpha 2$ for 1-oleoyl-2-acetyl$s n$-glycerol is 13 -fold lower than that for C16-PAF, which is similar to 8-fold difference shown by pPAF-AH for the same substrates (Table 2). However, in contrast to pPAF$\mathrm{AH}$ and PAF-AH(II), PAF-AH(Ib) $\alpha 2 / \alpha 2$ has relatively low activity toward tributyroylglycerol, 1(3)-monooctanoyl-racglycerol, dioctanoylglycerol, and dioctanoyl-PC (turnover numbers $<0.1 \mathrm{~s}^{-1}$, more than 32-fold lower than the turnover number for C16-PAF). In addition, PAF-AH(Ib) $\alpha 2 / \alpha 2$ hydrolyzes octyl acetate at a rate comparable to (1.7-fold lower) that for C16-PAF, and triacetylglycerol at a rate higher (12-fold) than that for C16-PAF. In contrast, pPAF-AH shows 88- and 1.5-fold lower rates for octyl acetate and triacetylglycerol, respectively, than that for C16-PAF (Table 2). PAF-AH(Ib) $\alpha 1 / \alpha 1$ hydrolyzes octyl acetate and triacetylglycerol 2- and 300-fold better than it does C16-PAF (Table 2), while it showed barely detectable hydrolysis $(<0.1$ $\mathrm{s}^{-1}$ ) of tributyroylglycerol, 1(3)-monooctanoyl-rac-glycerol, dioctanoylglycerol, dioctanoyl-PC, C18-PAF, 2-C16-PAF, and 1-oleoyl-2-acetyl-sn-glycerol. All together, the results show that PAF-AH(Ib) $\alpha 2 / \alpha 2$ and $\alpha 1 / \alpha 1$ have a strong preference for a short acetyl chain at a hydrolyzable position.

As shown in Figure 1, panel C, physarum PAF-AH, like pPAF-AH and PAF-AH(II), is able to hydrolyze a variety

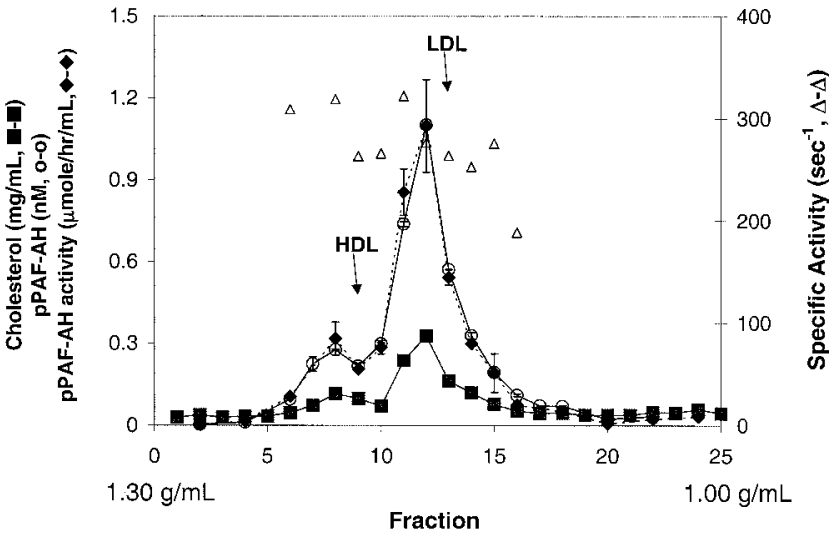

FIGURE 2: Association of endogenous pPAF-AH with HDL and LDL. Plasma $(200 \mu \mathrm{L})$ was ultracentrifuged in a $\mathrm{KBr}$ density gradient using a Beckman SW55Ti rotor at $55000 \mathrm{rpm}$ at $10{ }^{\circ} \mathrm{C}$ for $3 \mathrm{~h}$ as described in Materials and Methods. Fractions of 0.23 $\mathrm{mL}$ were collected by eluting the solution from the bottom at 1 $\mathrm{mL} / \mathrm{min}$ and were assayed for cholesterol ( $\boldsymbol{\square})$, pPAF-AH activity using $100 \mu \mathrm{M}(8.33 \mathrm{mCi} / \mathrm{mmol}) \mathrm{C} 16-\mathrm{PAF}$ in the absence of CHAPS $(\checkmark)$, and pPAF-AH protein by EIA $(O)$. The specific activity $(\Delta)$ is also calculated.

of lipid esters including dioctanoyl-PC and 2-C16-PAF (phospholipase $\mathrm{A}_{1}$ activity). As for pPAF-AH and PAF-AH(II), 1(3)-monooctanoyl-rac-glycerol is a poor substrate. Phyarum PAF-AH has greater preference for substrates with an $s n-3$ PC headgroup than pPAF-AH and PAF-AH(II), as 1,2-dioctanoyl-sn-glycerol and tributyroylglycerol show relatively very low hydrolysis rates compared to substrates containing PC.

Studies with Lipoprotein-Bound PPAF-AH. Since pPAF$\mathrm{AH}$ is bound to lipoproteins in plasma, it is of interest to determine if lipoprotein binding modifies the kinetic behavior of this enzyme. When the distribution of pPAF-AH among lipoproteins was examined after isolating the HDL and LDL fractions by $\mathrm{KBr}$-density gradient ultracentrifugation as described in the Materials and Methods, most of the PAFAH immunoreactivity (70\%) was found with LDL $(d=$ $1.04-1.07 \mathrm{~g} / \mathrm{mL})$ and the rest with HDL $(d=1.14-1.18$ $\mathrm{g} / \mathrm{mL}$ ) (Figure 2) as previously reported (8). The distribution of pPAF-AH among LDL density subfractions was also investigated after fractionation by the $\mathrm{D}_{2} \mathrm{O}$-density gradient ultracentrifugation procedure as described in Materials and Methods. The highest PAF-AH activity was detected in the dense LDL fractions $(d=1.043-1.046 \mathrm{~g} / \mathrm{mL})$ (Figure 3), which is similar to the previous findings (9).

We also examined the distribution of endogenous pPAF$\mathrm{AH}$ in plasma in the presence of varying concentrations of CHAPS to determine the detergent concentration required to dissociate the pPAF-AH from the lipoproteins. When plasma was chromatographed on a Superdex 200 size exclusion column in buffers containing varying concentra- 


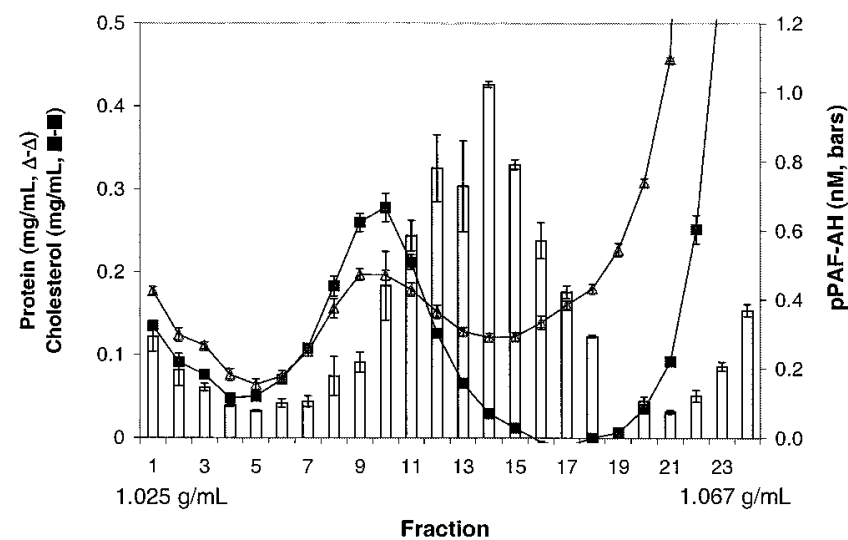

FIGURE 3: Distribution of LDL and pPAF-AH from isopycnic density gradient ultracentrifugation using a $\mathrm{D}_{2} \mathrm{O}$ gradient. Plasma was ultracentrifuged in a $\mathrm{D}_{2} \mathrm{O}-\mathrm{H}_{2} \mathrm{O}$ density gradient as described in Materials and Methods. Fractions of $0.40 \mathrm{~mL}$ were collected and each was assayed for protein $(\Delta)$, cholesterol $(\boldsymbol{\square})$, and pPAF$\mathrm{AH}$ protein determined by EIA (bar graph).

tions of CHAPS, lipoproteins eluted in the same fractions (LDL in fractions 15-20, HDL in fractions 23-28) in the presence of $0-6 \mathrm{mM}$ of CHAPS as shown by the cholesterol and protein distributions (Figure 4, panels A and B). On the other hand, most of the pPAF-AH activity that eluted with LDL (85-90\%) and HDL (10-15\%) in the presence of $0-2$ mM CHAPS (Figure 4, panel A) appeared in the fractions containing nonlipoprotein plasma proteins (fractions 2832 ) in the presence of 6 mM CHAPS (Figure 4, panel B). These results show that $6 \mathrm{mM}$ CHAPS was sufficient to fully dissociate PPAF-AH from the lipoproteins without noticeable disaggregation of the lipoproteins.

To compare the activity of lipoprotein-bound and CHAPSsolubilized pPAF-AH, we determined the specific activity of endogenous pPAF-AH in HDL fractions and in LDL subfractions in the presence and absence of $6 \mathrm{mM}$ CHAPS. We also measured the specific activity of recombinant pPAF$\mathrm{AH}$ in the presence of $6 \mathrm{mM}$ CHAPS. The amount of pPAF$\mathrm{AH}$ protein in each fraction was measured by EIA using antirecombinant pPAF-AH antibody, and the pPAF-AH enzymatic activity in each fraction was determined by the radiometric assay with $100 \mu \mathrm{M}\left[{ }^{3} \mathrm{H}\right] \mathrm{C} 16-\mathrm{PAF}$ in the presence and absence of 6 mM CHAPS. These numbers were used to obtain the specific activity, expressed in units of $\mathrm{s}^{-1}$. The specific activity of pPAF-AH under all these conditions did not change when the $\left[{ }^{3} \mathrm{H}\right] \mathrm{C} 16-\mathrm{PAF}$ concentration was decreased to $25 \mu \mathrm{M}$. Thus, with $100 \mu \mathrm{M}\left[{ }^{3} \mathrm{H}\right] \mathrm{C} 16-\mathrm{PAF}, V_{\text {max,app }}$ is being measured. As shown in Figure 2, the specific activity of endogenous lipoprotein-bound pPAF-AH measured with $\left[{ }^{3} \mathrm{H}\right]-$ C16-PAF in the absence of CHAPS is virtually constant across the HDL and LDL fractions. The specific activity of endogenous pPAF-AH does not change after dissociating the enzyme from LDL by the addition of $6 \mathrm{mM}$ CHAPS (Figure 5, panels A and B). Furthermore, the specific activity after adding an amount of recombinant pPAF-AH comparable to the endogenous amount in the dense LDL fraction $(d=$ $1.043-1.046 \mathrm{~g} / \mathrm{mL}$ ) is virtually identical to that measured for endogenous pPAF-AH in each LDL fraction (Figure 5, panels A and B). These results show that endogenous PPAF$\mathrm{AH}$ is not activated by binding to LDL.

The specific activity of recombinant pPAF-AH acting on
A

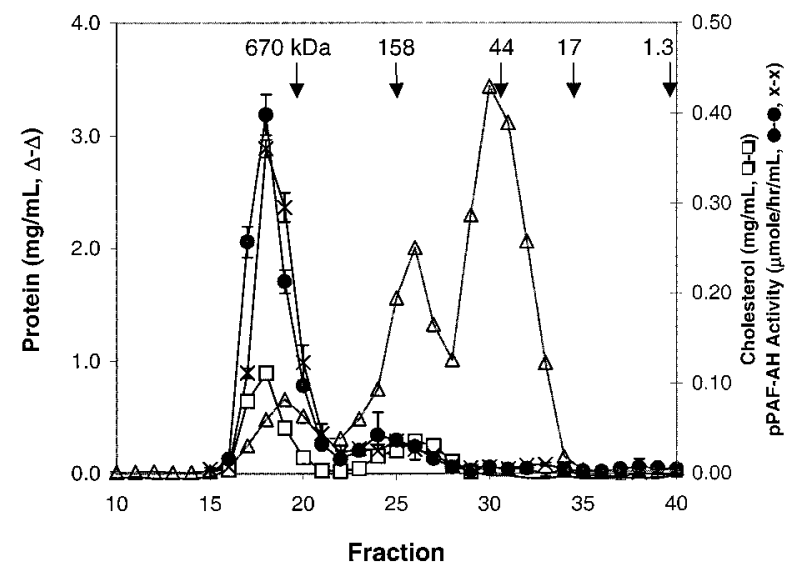

B

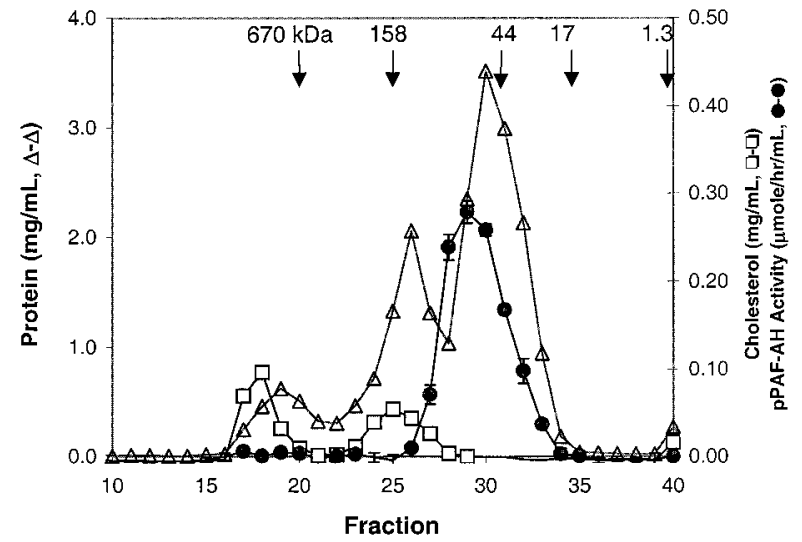

FIGURE 4: Dissociation of pPAF-AH from lipoproteins in the presence of CHAPS. Gel filtration chromatography was performed on $200 \mu \mathrm{L}$ of plasma ( $10 \mathrm{mg}$ of total protein) in pPAF-AH assay buffer ( $25 \mathrm{mM}$ Tris- $\mathrm{HCl}, \mathrm{pH} 7.5,0.5 \mathrm{M} \mathrm{NaCl}, 1 \mathrm{mM}$ EDTA) containing $0 \mathrm{mM}$ or $2 \mathrm{mM}$ CHAPS (A) or $6 \mathrm{mM}$ CHAPS (B) over a Superdex $200 \mathrm{HR} 10 / 30$ column $(10 \mathrm{~mm} \times 300 \mathrm{~mm}$, Pharmacia $)$ at a flow rate of $0.5 \mathrm{~mL} / \mathrm{min}$. The volume of each fraction was 0.5 $\mathrm{mL}$. Fractions were assayed for protein $(\triangle)$, cholesterol $(\square)$, and pPAF-AH activity ( for 0 and $6 \mathrm{mM}, \mathbf{X}$ for $2 \mathrm{mM}$ ) as described in Materials and Methods. Arrows indicate the elution positions of the molecular weight standards: thyroglobulin $(670 \mathrm{kDa})$, bovine gamma globulin $(158 \mathrm{kDa})$, ovalbumin $(44 \mathrm{kDa})$, myoglobin (17 $\mathrm{kDa})$, vitamin B-12 (1.3 kDa).

$\left[{ }^{3} \mathrm{H}\right] \mathrm{C} 16-\mathrm{PAF}$ measured in the presence of $6 \mathrm{mM}$ CHAPS and in the absence of lipoproteins was also measured, and a value of $290 \pm 21 \mathrm{~s}^{-1}$ for $\left.{ }^{3} \mathrm{H}\right] \mathrm{C} 16-\mathrm{PAF}$ was obtained. This value is virtually identical to that of endogenous lipoproteinbound pPAF-AH or to that for endogenous plus exogenously added recombinant pPAF-AH (Figure 5, panel B). All together, the results (Figures 2 and 5) show that endogenous pPAF-AH is not activated by binding to LDL or HDL. Further, endogenous pPAF-AH is not activated by binding to another protein component that may remain bound to pPAF-AH after dissociation from LDL by CHAPS.

Similar experiments as in Figure 5, panels A and B, were also carried out using $1.1 \mathrm{mM}\left[{ }^{3} \mathrm{H}\right] \mathrm{C} 10-\mathrm{PAF}$ instead of $\left[{ }^{3} \mathrm{H}\right]$ C16-PAF to monitor pPAF-AH activity (Figure 5, panel C). Studies at lower substrate concentrations establish that $V_{\text {max,app }}$ was being measured for all pPAF-AH samples in the presence of $1.1 \mathrm{mM}\left[{ }^{3} \mathrm{H}\right] \mathrm{C} 10-\mathrm{PAF}$. Again, LDL-bound pPAF-AH was found to have similar specific activity (average value across LDL fractions of $314 \pm 83 \mathrm{~s}^{-1}$ ) as the specific activity after an amount of recombinant enzyme was exogenously added $\left(337 \pm 21 \mathrm{~s}^{-1}\right)$ and as recombinant 


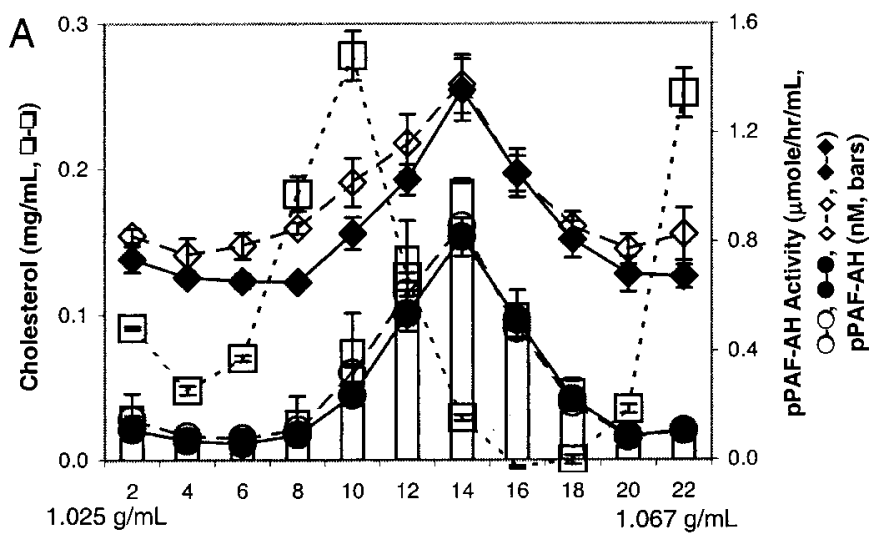

Fraction

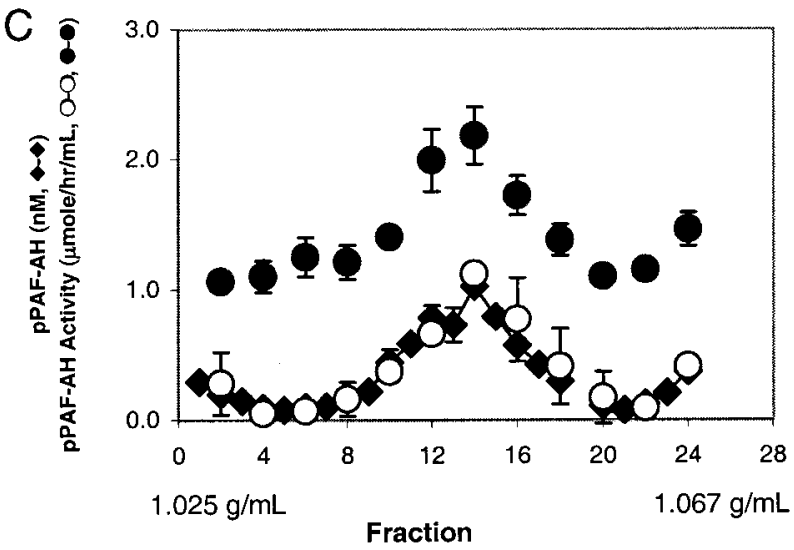

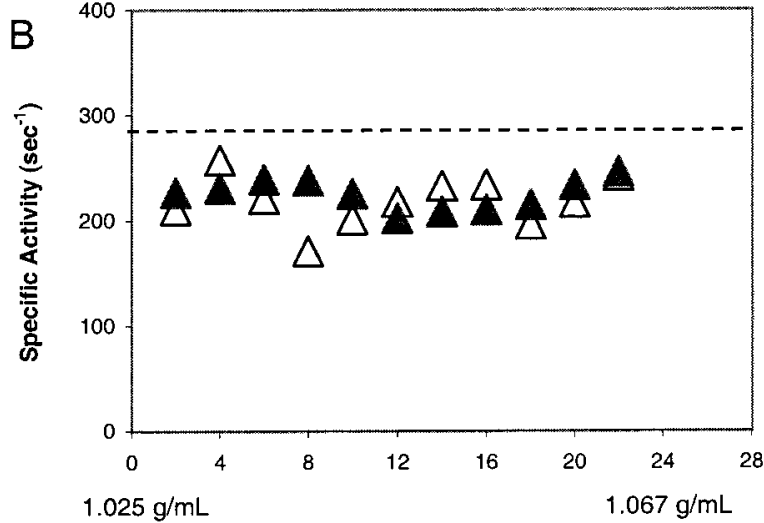

Fraction

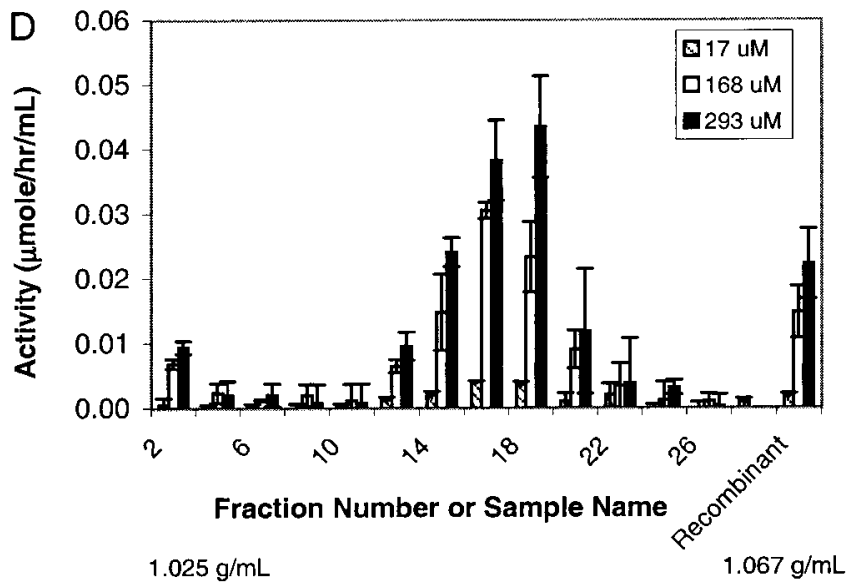

FIGURE 5: (A) Activity of LDL-bound and recombinant pPAF-AH in the presence and absence of CHAPS. LDL fractions from the $\mathrm{D}_{2} \mathrm{O}$ isopycnic density gradient ultracentrifugation were assayed for cholesterol ( $\square$ ) and pPAF-AH protein determined by EIA (bars). The enzymatic activity, measured with $100 \mu \mathrm{M}(8.33 \mathrm{mCi} / \mathrm{mmole})\left[{ }^{3} \mathrm{H}\right] \mathrm{C} 16-\mathrm{PAF}$, of endogenous pPAF-AH in the absence $(\mathrm{O})$ or presence of $6 \mathrm{mM}$ CHAPS (-) is shown as well as the total pPAF-AH activity after adding $3.7 \mathrm{ng}$ (final concentration, $0.74 \mathrm{nM}$ ) of recombinant pPAF-AH in the absence $(\diamond)$ or presence $(\diamond)$ of 6 mM CHAPS. The curve defined by $\bigcirc$ is almost superimposable on the curved defined by $\bullet$. (B) The specific activity of endogenous pPAF-AH $(\Delta)$ and of total pPAF-AH after adding $3.7 \mathrm{ng}$ (final concentration, $0.74 \mathrm{nM}$ ) of recombinant pPAF-AH ( $\mathbf{\Delta})$ in each lipoprotein fraction in the absence of CHAPS was calculated from the data in panel A. The dotted line shows the specific activity of recombinant pPAF-AH in $6 \mathrm{mM}$ CHAPS in the absence of lipoproteins (C) Activity of endogenous pPAF-AH in LDL fractions (same as those in panel A) measured with $1.1 \mathrm{mM}\left[{ }^{3} \mathrm{H}\right] \mathrm{C} 10-\mathrm{PAF}$ in the absence of CHAPS without (O) and with $3.7 \mathrm{ng}$ (final concentration, $0.74 \mathrm{nM}$ ) of exogenously added recombinant pPAF-AH (-). The amount of endogenous pPAF-AH protein (EIA assay) is also shown ( ). (D) The same LDL fractions as in panel A, were assayed for the hydrolysis of $17 \mu \mathrm{M}(4.9 \mathrm{mCi} / \mathrm{mmol}), 168 \mu \mathrm{M}(4.9$ $\mathrm{mCi} / \mathrm{mmol}), 293 \mu \mathrm{M}(2.8 \mathrm{mCi} / \mathrm{mmol})$ tributyroylglycerol[butyric- $1-{ }^{14} \mathrm{C}$ ] in the absence of CHAPS. The activity of $0.90 \mathrm{nM}$ recombinant pPAF-AH is shown on the right as a reference.

enzyme measured in the presence of 6 mM CHAPS $(424 \pm$ $\left.34 \mathrm{~s}^{-1}\right)$.

As noted above, recombinant pPAF-AH is able to efficiently hydrolyze tributyroylglycerol. To determine if LDLbound pPAF-AH also displays high activity toward short chain triacylglycerols, we developed a radiometric assay using tributyroylglycerol[butyric- $1-{ }^{14} \mathrm{C}$ ]. Data in Figure 5, panel D, show that LDL-bound endogenous pPAF-AH is able to hydrolyze tributyroylglycerol[butyric- $1-{ }^{14} \mathrm{C}$ ], and the specific activity for this reaction is similar to that for the same reaction catalyzed by recombinant $\mathrm{PPAF}-\mathrm{AH}$ measured in the presence of $6 \mathrm{mM}$ CHAPS and in the absence of lipoprotein. The specific activity for tributyroylglycerol[butyric- $1-{ }^{14} \mathrm{C}$ ] hydrolysis was $\sim 5 \%$ of the specific activity for the substrates $\left[{ }^{3} \mathrm{H}\right] \mathrm{C} 10-\mathrm{PAF}$ and $\left[{ }^{3} \mathrm{H}\right] \mathrm{C} 16-\mathrm{PAF}$. These results suggest that LDL-bound pPAF-AH is able to hydrolyze tributyroylglycerol, although we cannot rigorously rule out the possibility that this reaction is catalyzed by another enzyme present in the LDL fractions.

\section{DISCUSSION}

Substrate Specificities of Multiple PAF-AHs. Our previous study (25) showing that vesicle-bound pPAF-AH necessarily accesses its substrate from the aqueous phase raises the possibility that this enzyme can hydrolyze a number of esters other than PAF and closely related analogues that are considerably more soluble in the aqueous phase than are phospholipids with long $s n-1$ and $s n-2$ fatty acyl chains. As a prelude, we showed that the enzyme does not significantly recognize the choline group attached to the $s n-3$ phosphosphate of PAF (25). In the present study, we show that even the $s n-3$ phosphate is not required; 1-oleoyl-2-acetyl-snglycerol is a good pPAF-AH substrate. On the basis of all of the substrate specificity results, it appears that the minimal structural requirement for a good pPAF-AH substrate is the portion of a glyceride derivative that includes an $s n-2$ ester and a reasonably hydrophobic chain in the position occupied by the $s n-1$ chain (Figure 6). No group in the $s n-3$ position is required. In the context of this model, dibutyroyl-PC binds 

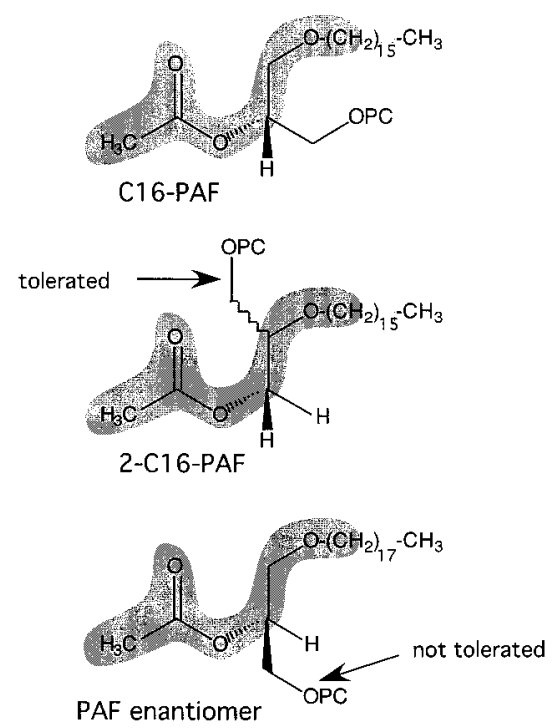

FIGURE 6: Molecular picture of the substrate specificity of pPAF$\mathrm{AH}$. (Top) The critical features of C16-PAF that are recognized by pPAF-AH include the $s n-2$ acetyl group, carbons 1 and 2 of the glycerol backbone, and a portion of the hydrophobic $s n-1$ chain (shaded in gray). (Middle) 2-C16-PAF contains the critical features of a good pPAF-AH substrate (shaded in gray) but carbon-3 of glycerol and the attached phosphorylcholine headgroup occupy a different position which is tolerated by the active site of pPAF$\mathrm{AH}$ (shown by arrow). Both stereoisomers of 2-C16-PAF are drawn, and both are good pPAF-AH substrates. (Bottom) Although the enantiomer of C18-PAF contains the critical features of a good pPAF-AH substrate (shaded in gray), the location of glycerol carbon-3 and the attached phosphorylcholine headgroup is apparently not tolerated at the active site (shown by arrow).

poorly to pPAF-AH because its $s n-1$ chain is too short. Butyl acetate binds weakly not because it lacks an $s n-3$ carbon but because the butyl chain does not provide a sufficiently hydrophobic group in the position analogous to the $s n-1$ chain of PAF. pPAF-AH displays phospholipase $\mathrm{A}_{1}$ activity toward 2-C16-PAF presumably because the $s n-1$ acetyl group of this substrate can occupy the same position on the enzyme as occupied by the acetyl group of PAF, and the $s n-2$ C16chain can occupy the position occupied by the $s n-1$ chain of PAF as long as the enzyme does not recognize the $s n-3$ headgroup and as long as the repositioned headgroup does not sterically clash with the enzyme (Figure 6). The enantiomer of PAF, 3-octadecyl-2-acetyl-sn-glycero-1-phosphocholine, also contains the elements of a good pPAF-AH substrate, but presumably presents its polar headgroup in a position that is not sterically tolerated at the active site (Figure 6). The other substrate specificity reported in Table 1 seems to fit this model including the fact that suitably hydrophobic triacylglycerols are good substrates for pPAF$\mathrm{AH}$. For all types of substrates, decreasing the aqueous phase solubility too far results in poor hydrolysis by pPAF-AH presumably because of the aqueous phase mechanism for the action of this enzyme. For this reason, it is difficult to make precise statements about the length of the fatty acyl chains that are tolerated by pPAF-AH. For example, data with dioctanoyl-PC show that an 8-carbon $s n$-2 fatty acyl chain is tolerated in the context of an 8-carbon $s n$-1 fatty acyl chain but not when the $s n-1$ chain is 16 carbons (19, 25).

On the whole, it seems that the classification of pPAF$\mathrm{AH}$ as a phospholipase $\mathrm{A}_{2}(38)$ or even as a phospholipase is misleading. On the basis of its primary sequence, it has been proposed that pPAF-AH is an $\alpha / \beta$ hydrolase reminiscent of a neutral lipase, distinct from the other known phospholipase $\mathrm{A}_{2} \mathrm{~S}$ which do not conform to the $\alpha / \beta$ hydrolase model $(26,39)$. Some researchers have used the name, lipoproteinassociated lipase for the enzyme $(40,41)$, but it is important to note that lipases are interfacial enzymes whereas pPAF$\mathrm{AH}$ is not.

The substrate specificity of pPAF-AH and PAF-AH(II) are very similar, suggesting that their physiological functions may be partially overlapping. The broad specificity of these enzymes raises the possibility that PAF and phospholipids with oxidatively truncated $s n-2$ chains are not the only physiological substrates for these enzymes. Although the concentrations of endogenous PAF in the blood stream of normal and pPAF-AH-deficient individuals have not been measured, a previous study showed that exogenously added PAF $\left(10^{-9} \mathrm{M}\right)$ has a half-life of $5 \mathrm{~min}$ in the plasma from normal subjects, whereas more than $95 \%$ of the PAF remained after $15 \mathrm{~min}$ in the plasma from pPAF-AH-deficient subjects (42). This result provides evidence that PAF is one of the in vivo substrates for pPAF-AH. Previous studies on PAF-AH(II) have shown that the enzyme senses the redox state of the cell and protects cells against oxidative stressinduced cell death presumably through the hydrolysis of oxidized phospholipids (43). Although it is questionable that the compounds used in this study are present in vivo, the structural requirements of a good substrate for the enzymes seem to be compatible with the anti-oxidative scavenger role of both enzymes. It seems reasonable for an enzyme to possess broad substrate specificity toward lipidic esters if it serves a protective role against oxidative stress since oxidative damage occurs not only from phospholipids but also from various types of compounds containing unsaturated bonds through uncontrolled free radical reactions (2).

The brain enzymes, PAF-AH(Ib) $\alpha 1 / \alpha 1$ and $\alpha 2 / \alpha 2$ have greater preference and selectivity toward an acetyl group than do the other PAF-AHs. PAF-AH(Ib) hydrolyzes an acetyl group not only from PAF and PAF analogues but also from other types of acetyl-containing esters such as octyl acetate or triacetylglycerol. Our results are consistent with a previous study showing strict substrate specificity of the enzyme for an acetate at the $s n-2$ position of a phospholipid (18). It has been proposed that PAF in the brain plays an important role as a messenger in excitatory neurotransmitter release, neuronal plasticity, memory formation, and long-term potentiation (reviewed in ref 44). It was also postulated that 1-Oalkyl-2-acetyl-phospholipids other than PAF such as alk-1enyl-acetyl-glycerophosphoethanolamine (2-acetylplasmalogen) may be physiological substrates for PAF$\mathrm{AH}(\mathrm{Ib})$ (45). A crystallographic study of PAF-AH(Ib) $\alpha 1 /$ $\alpha 1$ homodimers reveals that the active site structure can account for the exclusion of phospholipids with $s n-2$ acyl chains longer than acetyl (46).

Like pPAF-AH and PAF-AH(II), physarum PAF-AH displays broad substrate specificity, which raises the possibility that the function of this enzyme includes the hydrolysis of other hydrophobic esters other than PAF in lower eukaryotes. As with PAF-AH(II) and pPAF-AH, it has been speculated that physarum PAF-AH has an anti-oxidative role in the organism through its hydrolysis of oxidatively truncated phospholipids (24). 
Properties of Lipoprotein-Bound pPAF-AH. The specific activity of the following forms of pPAF-AH were found to be similar (less than 1.5-fold variation) when enzyme activity was assayed with the substrate $\left[{ }^{3} \mathrm{H}\right] \mathrm{C} 16-\mathrm{PAF}$ at $100 \mu \mathrm{M}$ : HDL- and LDL-bound endogenous pPAF-AH, and recombinant pPAF-AH added to LDL or free in solution in the presence of CHAPS (25). Likewise, similar specific activities (less than 2-fold variation) were seen with these forms of pPAF-AH when enzyme was assayed with $1.1 \mathrm{mM}\left[{ }^{3} \mathrm{H}\right] \mathrm{C} 10-$ PAF. Thus, binding of pPAF-AH to HDL or LDL does not significantly change the $V_{\text {max,app }}$ of this enzyme. In our previous study (25), we found that the specific activity of the recombinant pPAF-AH at $21{ }^{\circ} \mathrm{C}$ in the absence of vesicles, bound to zwitterionic phosphatidylcholine vesicles, and bound to anionic phosphatidylmethanol vesicles were similar (27, 15, and $16 \mathrm{~s}^{-1}$, respectively) in the presence of saturating PAF, and $\left(54,48\right.$, and $61 \mathrm{~s}^{-1}$, respectively) in the presence of saturating $\mathrm{C} 14-\mathrm{PAF}$. At $37{ }^{\circ} \mathrm{C}$, the specific activity for $\mathrm{C} 16-\mathrm{PAF}$ in the absence of the vesicles, was found to be $97 \pm 11 \mathrm{~s}^{-1}$. Again, these results show that the $V_{\text {max,app }}$ for pPAF-AH is not significantly altered by binding of the enzyme to a phospholipid interface.

In a previous study, it was suggested that the catalytic properties of pPAF-AH are influenced by its lipoprotein environment (8). It was shown that removal of LDL from human plasma by density gradient ultracentrifugation resulted in a 2.3- to 2.8-fold increase in the half-time for the degradation of PAF when added exogenously to plasma in the $10^{-9}-10^{-7} \mathrm{M}$ range. This increase in PAF hydrolysis half-time is consistent with the 2.7-fold decrease in total pPAF-AH activity measured under $V_{\text {max,app }}$ conditions (8). This result is consistent with the fact that the majority of pPAF-AH is bound to LDL (19, Figure 2). Interestingly, when HDL was depleted from plasma, again by density gradient ultracentrifugation, the half-time for exogenous PAF actually decreased by 1.4- to 1.9-fold, despite the fact that the total pPAF-AH activity decreased by 1.5 -fold (8). A possible explanation for this seemingly paradoxical result can be found in terms of the aqueous phase model for pPAF$\mathrm{AH}$ action (25). It is known that addition of a physiological concentration of serum albumin to albumin-free LDL containing bound PAF leads to a redistribution of most of the PAF to the albumin fraction (8). It is well established that the HDL fraction obtained from single density gradient ultracentrifugation of plasma contains significantly more albumin than does the LDL fraction. Thus, HDL-depleted plasma, prepared by this method, contains significantly less albumin than does nonfractionated plasma. This in turn suggests that the aqueous phase concentration of PAF is higher in HDL-depleted plasma than in whole plasma. This would result in a decrease in the half-time of PAF hydrolysis when exogenous PAF is added in the $10^{-9}-10^{-7} \mathrm{M}$ range, i.e., under nonsaturating conditions for pPAF-AH, because this enzyme is sensitive to the aqueous phase concentration of PAF. The aqueous phase model also accounts for the observation that the rate of hydrolysis of exogenously added PAF is slightly stimulated in cell-free plasma (8). Again, the cells provide a hydrophobic interface for PAF partitioning, leading to a decrease in aqueous phase PAF concentration. The approximately 2 -fold decrease in the half-time for the hydrolysis of exogenously added PAF in serum from a Tangier patient, which lacks HDL, is consistent with the approximately 2-fold higher levels of pPAF-AH measured in the Tangier patient as compared to that measured in plasma from normal patients (47). All together, the data with HDL and LDL depleted plasma do not provide evidence that the catalytic properties of pPAF-AH are influenced by its lipoprotein environment. Indeed, data in the present study argues that the $V_{\max \text {, app }}$ of lipoprotein-free and -bound pPAF$\mathrm{AH}$ are very similar. Our studies do not address whether the $K_{\mathrm{m}}$ for PAF hydrolysis by pPAF-AH is influenced by the lipoprotein environment. The difficulty with this issue is that values of $K_{\mathrm{m}}$ measured for pPAF-AH are apparent values (25), and values of $K_{\mathrm{m} \text {,app }}$ vary with changes in the concentration of all components in plasma, such as albumin, that can bind to PAF and lower its aqueous phase concentration.

There have been postulates that other isoforms of pPAFAH with different kinetic characteristics may exist in dense LDL fractions (9). However, our data show that the ratio of total pPAF-AH activity to total pPAF-AH protein detected by a monoclonal antibody prepared against recombinant pPAF-AH was the same across all lipoprotein fractions. Thus, there is no indication for the existence of multiple pPAF$\mathrm{AH}$ enzymes, and a single pPAF-AH is also supported by the study of Yoshida et al. which showed that the PAF-AHdeficient patient due to a single mutation in the pPAF-AH gene lacked the PAF degrading activity in the plasma (42).

\section{ACKNOWLEDGMENT}

The authors are grateful to Susan Pederson (ICOS) for the development of the quantitative EIA of pPAF-AH, to Matthew Taylor (ICOS) for technical assistance, and to Dr. H. Stewart Hendrickson, Elizabeth K. Hendrickson, and Dr. John Glomset (University of Washington) for the generous gifts of lipids. We also thank Dr. Kohei Yokoyama (University of Washington) for helpful comments on the manuscript.

\section{REFERENCES}

1. Prescott, S. M., Zimmerman, G. A., Stafforini, D. M., and McIntyre, T. M. (2000) Annu. Rev. Biochem. 69, 419-45.

2. Esterbauer, H., Gebicki, J., Puhl, H., and Jurgens, G. (1992) Free Radical Biol. Med. 13, 341-90.

3. Heery, J. M., Kozak, M., Stafforini, D. M., Jones, D. A., Zimmerman, G. A., McIntyre, T. M., and Prescott, S. M. (1995) J. Clin. Invest. 96, 2322-30.

4. Yamada, Y., Yoshida, H., Ichihara, S., Imaizumi, T., Satoh, K., and Yokota, M. (2000) Atherosclerosis 150, 209-16.

5. Stafforini, D. M., McIntyre, T. M., Zimmerman, G. A., and Prescott, S. M. (1997) J. Biol. Chem. 272, 17895-8.

6. Yamada, Y., and Yokota, M. (1998) Jpn. Circ. J. 62, 32835.

7. Ho, Y. S., Sheffield, P. J., Masuyama, J., Arai, H., Li, J., Aoki, J., Inoue, K., Derewenda, U., and Derewenda, Z. S. (1999) Protein Eng. 12, 693-700.

8. Stafforini, D. M., McIntyre, T. M., Carter, M. E., and Prescott, S. M. (1987) J. Biol. Chem. 262, 4215-22.

9. Tselepis, A. D., Dentan, C., Karabina, S. A., Chapman, M. J., and Ninio, E. (1995) Arterioscler. Thromb. Vasc. Biol. 15, 1764-73.

10. McCall, M. R., La Belle, M., Forte, T. M., Krauss, R. M., Takanami, Y., and Tribble, D. L. (1999) Biochim. Biophys. Acta 1437, 23-36.

11. Stafforini, D. M., Numao, T., Tsodikov, A., Vaitkus, D., Fukuda, T., Watanabe, N., Fueki, N., McIntyre, T. M., Zimmerman, G. A., Makino, S., and Prescott, S. M. (1999) J. Clin. Invest. 103, 989-97. 
12. Kruse, S., Mao, X. Q., Heinzmann, A., Blattmann, S., Roberts, M. H., Braun, S., Gao, P. S., Forster, J., Kuehr, J., Hopkin, J. M., Shirakawa, T., and Deichmann, K. A. (2000) Am. J. Hum. Genet. 66, 1522-1530.

13. Miwa, M., Miyake, T., Yamanaka, T., Sugatani, J., Suzuki, Y., Sakata, S., Araki, Y., and Matsumoto, M. (1988) J. Clin. Invest. 82, 1983-91.

14. Hofbauer, B., Saluja, A. K., Bhatia, M., Frossard, J. L., Lee, H. S., Bhagat, L., and Steer, M. L. (1998) Gastroenterology $115,1238-47$

15. Henderson, W. R., Jr., Lu, J., Poole, K. M., Dietsch, G. N., and Chi, E. Y. (2000) J. Immunol. 164, 3360-7.

16. Fukuda, Y., Kawashima, H., Saito, K., Inomata, N., Matsui, M., and Nakanishi, T. (2000) Eur. J. Pharmacol. 390, 2037.

17. ICOS. (2000) ICOS Corporation Press Release, April 20.

18. Hattori, K., Hattori, M., Adachi, H., Tsujimoto, M., Arai, H., and Inoue, K. (1995) J. Biol. Chem. 270, 22308-13.

19. Stafforini, D. M., Prescott, S. M., and McIntyre, T. M. (1987) J. Biol. Chem. 262, 4223-30.

20. Stremler, K. E., Stafforini, D. M., Prescott, S. M., Zimmerman, G. A., and McIntyre, T. M. (1989) J. Biol. Chem. 264, 53314.

21. Hattori, M., Adachi, H., Tsujimoto, M., Arai, H., and Inoue, K. (1994) Nature 370, 216-8.

22. Hattori, K., Adachi, H., Matsuzawa, A., Yamamoto, K., Tsujimoto, M., Aoki, J., Hattori, M., Arai, H., and Inoue, K. (1996) J. Biol. Chem. 271, 33032-8.

23. Manya, H., Aoki, J., Watanabe, M., Adachi, T., Asou, H., Inoue, Y., Arai, H., and Inoue, K. (1998) J. Biol. Chem. 273, $18567-72$

24. Umezu, M., Aoki, J., Matsuzawa, A., Dohmae, N., Kobayashi, T., Takio, K., Murakami-Murofushi, K., Arai, H., and Inoue, $\mathrm{K}$., manuscript in preparation.

25. Min, J. H., Jain, M. K., Wilder, C., Paul, L., Apitz-Castro, R., Aspleaf, D. C., and Gelb, M. H. (1999) Biochemistry 38, 12935-42.

26. Tjoelker, L. W., Eberhardt, C., Unger, J., Trong, H. L., Zimmerman, G. A., McIntyre, T. M., Stafforini, D. M., Prescott, S. M., and Gray, P. W. (1995) J. Biol. Chem. 270, $25481-7$.

27. Hattori, M., Adachi, H., Aoki, J., Tsujimoto, M., Arai, H., and Inoue, K. (1995) J. Biol. Chem. 270, 31345-52.

28. Heymans, F., Michel, E., Borrel, M. C., Wichrowski, B. Godfroid, J. J., Convert, O., Coeffier, E., Tence, M., Benveniste, J. (1981) Biochim. Biophys. Acta 666, 230-237.
29. Ames, B. N. (1966) Methods Enzymol. 8, 115-118.

30. Jain, M. K., and Gelb, M. H. (1991) Methods Enzymol. 197, $112-125$.

31. Smith, P. K., Krohn, R. I., Hermanson, G. T., Mallia, A. K., Gartner, F. H., Provenzano, M. D., Fujimoto, E. K., Goeke, N. M., Olson, B. J., and Klenk, D. C. (1985) Anal. Biochem. $150,76-85$.

32. Hallberg, C., Haden, M., Bergstrom, M., Hanson, G., Pettersson, K., Westerlund, C., Bondjers, G., Ostlund-Lindqvist, A. M., and Camejo, G. (1994) J. Lipid Res. 35, 1-9.

33. De Jong, A. S., Van Kessel-van Vark, M., and Raap, A. K. (1985) Histochem. J. 17, 1119-30.

34. Kelley, J. L., and Kruski, A. W. (1986) Methods Enzymol. $128,170-81$.

35. Stafforini, D. M., Prescott, S. M., and McIntyre, T. M. (1991) Methods Enzymol. 197, 411-25.

36. Stremler, K. E., Stafforini, D. M., Prescott, S. M., and McIntyre, T. M. (1991) J. Biol. Chem. 266, 11095-103.

37. Shima, M., Yohdoh, K., Yamaguchi, M., Kimura, Y., Adachi, S., and Matsuno, R. (1997) Biosci. Biotechnol. Biochem. 61, 1150-5.

38. Dennis, E. A. (1997) Trends Biochem. Sci. 22, 1-2.

39. Wei, Y., Swenson, L., Castro, C., Derewenda, U., Minor, W., Arai, H., Aoki, J., Inoue, K., Servin-Gonzalez, L., and Derewenda, Z. S. (1998) Structure 6, 511-9.

40. Macphee, C. H., Milliner, K., Moores, K., Tew, D. G. (1996) Pharmacol. Rev. Commun. 8, 309-315.

41. Tew, D. G., Southan, C., Rice, S. Q., Lawrence, M. P., Li, H., Boyd, H. F., Moores, K., Gloger, I. S., and Macphee, C. H. (1996) Arterioscler. Thromb. Vasc. Biol. 16, 591-9.

42. Yoshida, H., Satoh, K., Koyama, M., Hiramoto, M., and Takamatsu, S. (1996) Am. J. Hematol. 53, 158-64.

43. Matsuzawa, A., Hattori, K., Aoki, J., Arai, H., and Inoue, K. (1997) J. Biol. Chem. 272, 32315-20.

44. Tjoelker, L. W., and Stafforini, D. M. (2000) Biochim. Biophys. Acta 1488, 102-23.

45. Manya, H., Aoki, J., Kato, H., Ishii, J., Hino, S., Arai, H., and Inoue, K. (1999) J. Biol. Chem. 274, 31827-32.

46. Ho, Y. S., Swenson, L., Derewenda, U., Serre, L., Wei, Y., Dauter, Z., Hattori, M., Adachi, T., Aoki, J., Arai, H., Inoue, K., and Derewenda, Z. S. (1997) Nature 385, 89-93.

47. Stafforini, D. M., Carter, M. E., Zimmerman, G. A., McIntyre, T. M., and Prescott, S. M. (1989) Proc. Natl. Acad. Sci. U.S.A. $86,2393-7$.

BI002600G 